\title{
Physical vulnerability modelling in natural hazard risk assessment
}

\author{
J. Douglas \\ BRGM - ARN/RIS, 3 avenue C. Guillemin, BP 36009, 45060 ORLEANS Cedex 2, France \\ Received: 3 November 2006 - Revised: 6 February 2007 - Accepted: 27 March 2007 - Published: 5 April 2007
}

\begin{abstract}
An evaluation of the risk to an exposed element from a hazardous event requires a consideration of the element's vulnerability, which expresses its propensity to suffer damage. This concept allows the assessed level of hazard to be translated to an estimated level of risk and is often used to evaluate the risk from earthquakes and cyclones. However, for other natural perils, such as mass movements, coastal erosion and volcanoes, the incorporation of vulnerability within risk assessment is not well established and consequently quantitative risk estimations are not often made. This impedes the study of the relative contributions from different hazards to the overall risk at a site.

Physical vulnerability is poorly modelled for many reasons: the cause of human casualties (from the event itself rather than by building damage); lack of observational data on the hazard, the elements at risk and the induced damage; the complexity of the structural damage mechanisms; the temporal and geographical scales; and the ability to modify the hazard level. Many of these causes are related to the nature of the peril therefore for some hazards, such as coastal erosion, the benefits of considering an element's physical vulnerability may be limited. However, for hazards such as volcanoes and mass movements the modelling of vulnerability should be improved by, for example, following the efforts made in earthquake risk assessment. For example, additional observational data on induced building damage and the hazardous event should be routinely collected and correlated and also numerical modelling of building behaviour during a damaging event should be attempted.
\end{abstract}

\section{Introduction}

There has been growing interest in conducting multi-risk assessments recently. For example, numerous EC-funded Sixth Framework Programme Integrated Projects, such as from the information technology viewpoint: ORCHESTRA (2006), OASIS (2006) and WIN (2006) and with regards data collec-

Correspondence to: J. Douglas

(j.douglas@brgm.fr) tion: PREVIEW (2006), are investigating aspects of multirisk management. The software applications developed for the American HAZUS-MH (FEMA, 2003), the New Zealand RiskScape (King and Bell, 2005) and the French ARMAGEDOM (Sedan and Mirgon, 2003) projects are being developed in the direction of multi-risk evaluation. Also currently on going is the Risk Map Germany (2006) initiative. An evaluation of the risk to an exposed element from a given hazard requires a consideration of the element's vulnerability, expressing its propensity to suffer damage. This concept allows the assessed level of hazard to be translated to an estimated level of risk. This approach is well established within a few risk domains, such as earthquake risk where numerous fragility curves (expressing the damage level to a building given, for example, the amplitude of ground shaking) exist. However, for many hazards, such as mass movements, coastal erosion and volcanoes, the incorporation of vulnerability within risk assessment is not well-established and few, if any, fragility curves have been developed (e.g. Douglas, 2005). This article discusses reasons for this difference in approach, which are important if it is hoped to develop a consistent method of risk assessment for various risks and, in particular, if it is hoped that the techniques applied in earthquake risk evaluation can be used for other types of risks.

This article is only concerned with risks related to natural hazards, e.g.: earthquakes, landslides, tsunamis, coastal erosion and floods. Borst et al. (2006), for example, develop a methodology for the assessment of man-made risks. Only the modelling of physical vulnerability, and not the social vulnerability of populations, is discussed here.

The following section briefly discusses the methods commonly adopted to assess risk for different natural hazards, contrasting the approach usually followed for earthquake risk (where fragility curves are used) to that adopted in other risk domains (where fragility curves are rarely used). Section 3 discusses the reasons why the vulnerability of elements at risk is not often considered within risk assessments for natural hazards other than earthquakes. The article ends with some conclusions and suggestions.

Published by Copernicus GmbH on behalf of the European Geosciences Union. 


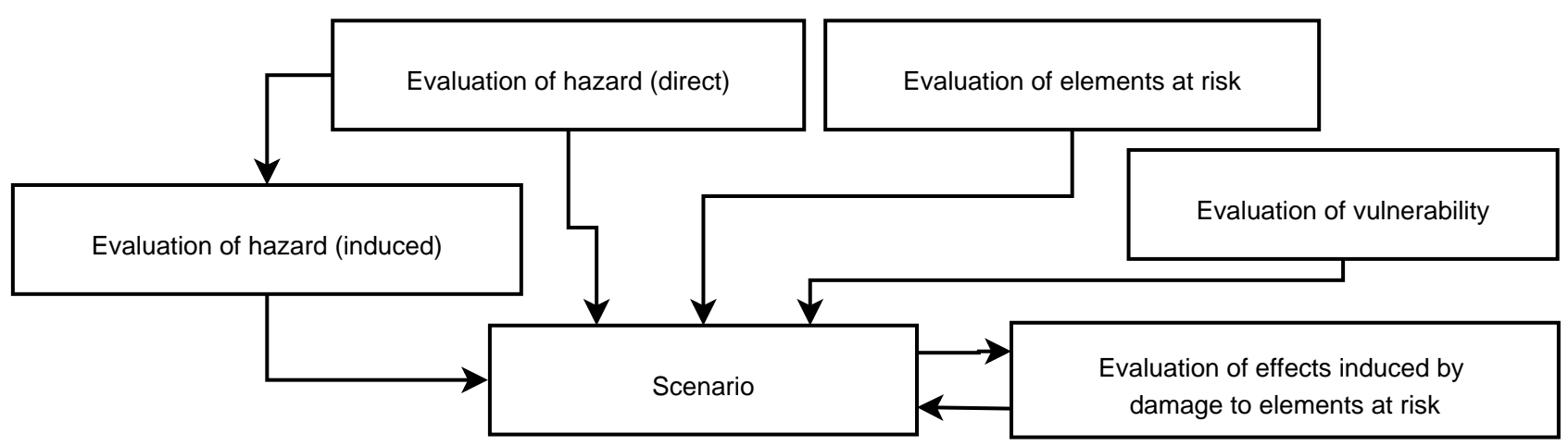

Fig. 1. The general procedure followed for the evaluation of risk for one scenario.

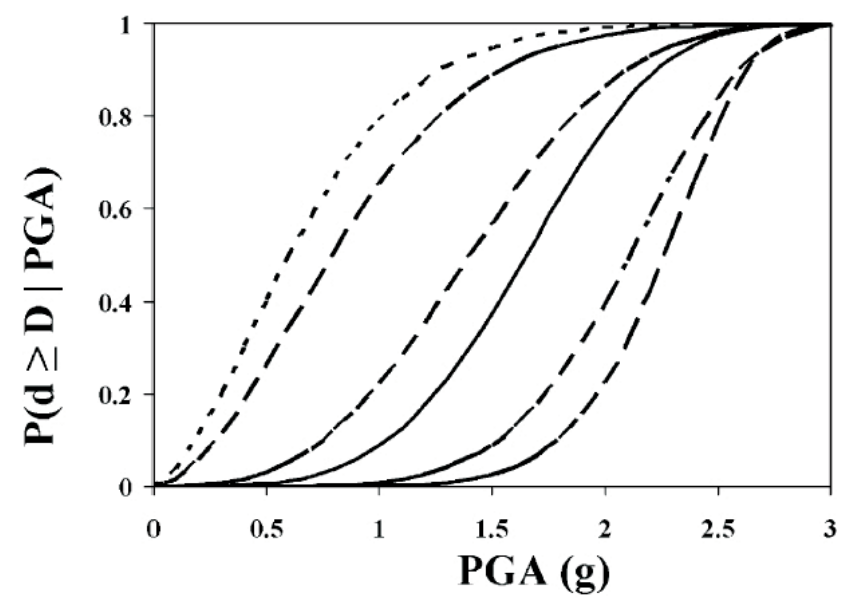

Fig. 2. A set of fragility curves for reinforced-concrete buildings for the prediction of earthquake damage of different severities (Rossetto and Elnashai, 2003). PGA is peak ground acceleration (the hazard parameter) and the $y$-axis gives the probability of exceeding a given damage state.

\section{Risk assessments for natural hazards}

Figure 1 summarises the main aspects to be considered within a risk assessment. The way the hazard is characterised within the step "Evaluation of the hazard" is generally similar for different natural phenomena. The hazard is commonly characterised in terms of the probability of a measurable physical parameter (or, occasionally, parameters) exceeding a certain threshold during a period of time. For example, the conference proceedings edited by Vecchia (2001) shows that this is a common approach for many natural hazards. The step 'Evaluation of elements at risk' is mainly independent of the type of risk considered since it concerns the collection and use of information such as the cost of a building and its occupancy rate. Such information expresses the level of exposure, defined in natural hazard risk assessments by the characteristics of the population and physical environment at risk. In contrast, the stage "Evaluation of vulnerabil- ity" and the combination of the hazard and the vulnerability to obtain the risk (the item entitled 'Scenario') differs significantly between hazards.

Within earthquake risk assessments, fragility curves, which express the probable damage to an element at risk given a level of hazard (characterised as within the associated hazard assessment), are used to estimate the expected level of damage (e.g. Fig. 2). This approach is then applied to different types of elements at risk (with potentially different fragility curves due to differing vulnerabilities) and the results combined in order to obtain an estimate of the level of risk (e.g. Bommer et al., 2002). One type of risk assessment similar to that for earthquakes is the assessment of risk from cyclones (e.g. Stewart, 2003) probably since they have similar features to earthquakes, unlike other types of events.

Within risk assessment for most other types of natural hazards, fragility curves are not used but the hazard levels are plotted on maps displaying the elements at risk and their vulnerability (often classified as low, medium or high) (e.g. Dominey-Howes and Papathoma, 2006). Such types of assessments provide qualitative guidance as to the level of risk due to a particular hazard but cannot be used to provide quantitative estimates of direct economic loss, for example. However, even when fragility curves are used predicted losses are still associated with large uncertainties (e.g. Crowley et al., 2005).

For landslide risk assessments Glade (2003) finds that there is a lack of studies on the vulnerability of elements and therefore fragility curves are rarely used. Current methods assume that if a landslide occurs then the buildings in its path will be total destroyed (this assumes a constant fragility curve equal to unity for all non-zero values of the hazard parameter) although some more complex approaches have been recently attempted (Glade, 2003). Bahoken (2003) present a number of intensity scales for different types of mass movement, including landslides and rock falls. These intensity scales give the expected damage to particular elements at risk for different intensities of movement, characterised in terms of one or two parameters (for landslides they are volume 
and depth of slide), which could be converted into fragility curves. Cardinali et al. (2002) and Bell and Glade (2004) do use basic fragility curves within their analyses although these are based mainly on expert judgement. Green and Rose (2005) note that although volcano hazard maps are quite common, volcano risk maps are very rare.

An interesting recent proposal to generalise hazard estimates and fragility functions derived for one risk to enable them to be used for another is made by Hollenstein (2005). In this method hazard estimates are defined in terms of a set of common base parameters (for example acceleration, pressure and temperature change) and fragility functions are defined in terms of these common parameters so that they are applicable to all risks. To convert from the established parameters that define hazard (e.g. macroseismic intensity for earthquakes and water depth for floods) wrapper functions need to be developed. Although this method is appealing, at present it has never been applied in practice and is still under development.

\section{Reasons for not modelling vulnerability}

Vulnerability is modelled in various ways within risk assessments for different natural hazards. Often it is not considered at all and only the level of hazard is evaluated. The possible, often interlinked, reasons for this are discussed below by contrasting the situation for different risks to that of earthquake risk assessment, where vulnerability is commonly modelled.

\subsection{Ability to change hazard or exposure level}

Earthquakes cannot be prevented or predicted nor can the shaking that occurs be reduced. In addition, there is no warning for earthquake occurrence and hence people cannot be evacuated from the area at risk. Therefore in order to manage the risk it is necessary to alter the exposure (e.g. through land-use planning) or reduce the vulnerability of exposed elements (e.g. through structural retrofitting). In order to accomplish these tasks in a cost-effective manner a quantitative assessment of the risk in a region needs to be conducted, hence fragility curves are required.

For some other hazards, for example some forms of coastal erosion, it is possible to lower the level of hazard at a given location through an engineering approach, for example the construction of a sea wall to prevent erosion. Also for some hazards, e.g. some landslides, it is possible to spot warning signs of a future event and hence evacuate the population at risk. This ability to mitigate the hazard or evacuate people means that there is less incentive to assess the impact of an event, by using fragility curves for example, because it may be possible to prevent its occurrence.

\subsection{Time and geographical scale}

Earthquake damage usually occurs rapidly during the few seconds of strong shaking. This rapidity of occurrence, and the lack of warning, leads to human causalities. Hence there is a strong social need to construct fragility curves in order to be able to translate expected building damage into expected number of deaths and injuries during an earthquake scenario. In addition, the lack of warning and the possible large geographical scale of the area affected by an earthquake, means that it is important to predict how many buildings may be damaged in order to estimate the number of homeless and those requiring medical treatment. The situation for some hazards differs, as discussed above, because through careful monitoring, short- and mid-term forecasting is sometimes possible, e.g. for volcanoes (Marzocchi et al., 2004).

Building damage from some other hazards, for example coastal erosion or ground creep, happens over a much longer time scale. Therefore, people are not in physical danger from the event and also, since they are slower events and are often smaller, there is time to plan the evacuation of people from their homes and to provide alternative accommodation. In this case, there is a less pressing need for fragility curves.

Some hazardous events, such as rock falls, affect a limited area, perhaps only comprising a handful of buildings. Therefore it is not important to compute the level of damage induced but simply to know which area needs to be evacuated. For these types of event the level of exposure can be altered due to their small geographical scale; this is less easy to do for earthquakes, which can affect a large region.

\subsection{Different cause for human losses}

As discussed above, one major difference between earthquakes and many other natural hazards is that earthquakes themselves rarely kill, rather it is the damage to a building that then causes deaths and injuries, whereas for other natural hazards, e.g. landslides or volcanoes, the event itself can inflict human losses. Hence there is a much greater requirement to construct fragility curves for building damage for earthquakes than for other types of hazard, in order to estimate human losses (an important part of most risk assessments). For some hazards, such as floods, where the event itself can cause death or injuries, there exist curves predicting the danger to life as a function of the intensity of the event (e.g. Ramsbottom et al., 2003). These can be thought to be equivalent to fragility curves for the assessment of loss of life.

\subsection{Various causes of damage}

Bird and Bommer (2004) find that in $88 \%$ of the fifty recent damaging earthquakes they investigate, damage due to ground shaking was responsible for the majority of damage; other causes of damage (such as liquefaction, surface 
rupture or seismically-triggered landslides) were responsible for most damage in only a few events. Therefore for earthquakes fragility curves usually need only to be developed to predict the damage caused by various levels of ground shaking.

This situation where damage is mainly due to a single cause is not true for hazards such as volcanoes, where buildings can be damaged by (Marzocchi et al., 2004): horizontal pressures and temperatures of pyroclastic and lava flows, vertical load of ash fall, lava, ground deformations and shaking due to volcanic activity and people can be killed by noxious gases or other effects; or for mass movements, where the cause of damage depends on the type of material (e.g. rock), speed and type of movement (e.g. fall) and volume. In volcano risk assessment, work is being undertaken to develop separate fragility curves for different types of effects (Spence et al., 2004, 2005).

\subsection{Lack of observational data}

When earthquakes occur it is common to send field investigation teams to study and record damage caused to structures. These data are then openly published in reports and articles, and can then be used, after estimating the ground motion that occurred at the locations of damage (see below), to develop empirical fragility curves by correlating the level of earthquake ground motion to the damage level of a particular type of structure (e.g. Rossetto and Elnashai, 2003). The fragility curves thus developed are then employed within risk assessments to estimate the structural damage in future events. However, even for earthquake risk, the lack of highquality observational evidence means that some of the most commonly used sets of fragility curves (e.g. ATC-13, 1985) were developed using expert judgement.

This practice of field missions to assess, in detail, building damage is not as well established for other types of events where often the physical phenomenon itself is the main interest of the mission. In addition, it is difficult to back analyse other events in order to estimate the event characteristics that a given element at risk was subjected; unlike for earthquakes where accelerograms close to a damaged building can be used. For example, one important parameter for analysing the effect of tsunamis is the intensity of the tsunami-induced current but this information is difficult to obtain due to a lack of current-measuring instruments.

In addition, fewer buildings are usually damaged by a single event, such as a landslide, than by a large earthquake and consequently observations from many events must be combined in order to develop empirical fragility curves. For example, Coburn et al. (1994) reproduce $f: N$ curves (i.e. number of people killed in one event, $f$, versus number of events recorded 1900-1975, $N$ ) for different natural disasters, which shows that earthquakes, floods and storms (the risks with the most well-developed use of fragility curves) kill many more people in a single event than volcanoes or landslides/avalanches (for which fragility curves are not commonly used).

The estimation of tsunami risk before the 2004 Indian Ocean earthquake and subsequent tsunami was severely limited by a lack of quantitative observational data from damaging tsunamis due to their long return periods. Also it could be argued that there was little research interest in assessing possible tsunami damage before this disaster since significant damage from tsunamis had been rare during the late 20th century compared with damage from other natural events. However, since the 2004 Indian Ocean tsunami, studies have been published proposing fragility curves using data from this event (Peiris, 2006).

\subsection{Complexity of modelling effect of event on element}

Earthquake risk assessment is still commonly conducted using a single ground-motion parameter that characterises the amplitude of the ground shaking, often peak ground acceleration or a response spectral ordinate at a period of interest (e.g. the natural period of the building). Although these methods are relatively simple they give reasonably accurate damage estimates. Research is currently being undertaken to reduce the uncertainty in predicting the level of building damage given a level of earthquake hazard through the incorporation of other ground-motion characteristics, such as duration of shaking (e.g. Bommer et al., 2004), within fragility curves. These more sophisticated approaches are, however, not yet commonly applied in practice.

For other risks, in contrast, there are numerous event characteristics that are valuable in predicting the damage that occurs to an element at risk. Cardinali et al. (2002) state that there are at least four characteristics of landslides that need to be included for a correct parameterization of the hazard (these would then consequently need to be considered in the development of fragility curves), namely: size, shape, velocity and momentum. Therefore, characterising other perils is often more difficult than characterising earthquake hazard.

In addition, simplified models, with few input parameters, are available that can be used to evaluate the response of a building to earthquake shaking. Such simplified models do not exist to model the response of a building to other types of events and complex methods (e.g. finite elements) need to be used. These complex approaches are computational expensive and are not adapted to parametric modelling such as is required to develop fragility curves.

\subsection{Lack of structural input data}

As mentioned above, within earthquake risk assessments structures are usually modelled using highly simplified models (such as elastic single-degree-of-freedom systems), which nevertheless provide reasonably accurate results. Straightforward procedures for providing input parameters to these simplified models have been developed over the 
relatively long history of earthquake engineering. These methods usually classify buildings based on their age, construction material, number of storeys and possibly other characteristics than can be found by visual, external inspection of the building. In addition, building databases developed for other purposes contain useful parameters for the assessment of earthquake vulnerability. These techniques are therefore relatively fast and cheap and hence can be readily applied in order to undertake a risk assessment.

For other hazards, the type of information required for modelling is more difficult to obtain, thereby restricting the use of such models and consequently the development of fragility curves. For example, for predicting landslide damage it is important to know foundation properties, which cannot be determined simply by external, visual inspection. However, it may be possible to assume a type of foundation based on other characteristics that can be more easily determined, such as the information that is collected for earthquake vulnerability assessment: age, building type and number of storeys.

\subsection{Repairability of buildings}

One purpose of an earthquake risk assessment is to estimate how many buildings will be damaged but will be able to be repaired in order to calculate the cost of reconstruction after an event. This requirement means that most approaches adopt a scale with a handful of damage classes (e.g. undamaged, light, moderate, severe, near collapse and collapse) in which the buildings probable performance during an earthquake will fall. Buildings predicted to have low levels of damage are assumed to be repairable.

For other hazards, such as tsunamis or pyroclastic flows, there is little chance that a building exposed to the full force of the event will be able to be repaired. For example, King and Bell (2005) note that the fragility curves for low-rise buildings used in the RiskScape model for flood and tsunami inundation are very sensitive to the exact height of the water: the building is undamaged if the water is below the lowest floor level but requires repairs or must be completely replaced if the water is $1.2 \mathrm{~m}$ above this level. This shows that the fragility curve is step-like and hence there is little benefit gained from using a complex fragility curve rather than simply predicting the location of this critical water depth.

\section{Conclusions}

Comparisons between the risk posed by different natural hazards to a population are more correctly performed by examining risk rather than hazard indicators since hazard parameters for different types of perils cannot be readily compared, as they often measure different physical quantities, whereas risk parameters can. For example, a certain level of earthquake ground acceleration cannot be compared to a given flood water level whereas the expected number of damaged buildings from an earthquake or a flood can. In addition, risk parameters are what are of interest to the population.

However, in this brief article it is shown that, although required to undertake risk assessments, fragility curves have rarely been developed for hazards other than earthquakes and cyclones. It is proposed here that a combination of various reasons explain this deficiency. Some of these are due to a lack of observational data and consequently, with significant investment in data collection, these difficulties could be reduced. However, even if large sensor networks are installed and extensive post-event field missions are conducted, the return periods of damaging events are often many decades and therefore it is likely that observational data will not be available for risk calibration purposes for a long time.

Another difficulty in developing fragility curves is the lack of input data for the structural model. To try to overcome this, research could be undertaken to try to make use of the comprehensive datasets of structural information collected for earthquake risk assessments perhaps by developing empirical correlations between required and known structural parameters.

For certain types of natural phenomena (e.g. coastal erosion) due to characteristics different to those of earthquakes the concept of explicitly using fragility curves may not be appropriate and the current method of hazard assessment coupled with an consideration of the exposure of vulnerable elements may be sufficient. In addition, the goal of assessments for such hazards is different to that for earthquakes. They seek to pinpoint the area at danger for evacuation purposes or to intervene using an engineering approach to prevent the occurrence of the possible event rather than to estimate the possible impact of events (such as earthquakes) that cannot be predicted nor prevented.

Acknowledgements. This study was funded by internal BRGM research projects. I thank A. King for information on RiskScape, M. Pagani for comments on an early draft, D. Idier for an internal review of a previous draft and other colleagues for sharing their views on the subjects addressed in this article. In addition, I am grateful to W. Smith and three anonymous reviewers for their critical comments, which led to improvements.

Edited by: T. Glade

Reviewed by: W. Smith and three other referees

\section{References}

ATC-13: Earthquake damage evaluation data for California, Tech. Rep. ATC-13, Applied Technology Council, Redwood City, Palo Alto, California, USA, 1985.

Bahoken, F.: Determination dune echelle dintensité en 5 niveaux par types de phenomenes naturals - phase 6: Validation des echelles - annex 4 - guides d'utilisation des echelles mouvements de terrain., Tech. rep., Geosciences Consultants s.a.r.l., Bagneux, France, in French, 2003. 
Bell, R. and Glade, T.: Quantitative risk analysis for landslides - Examples from Bíldudalur, NW-Iceland, Nat. Hazards Earth Syst. Sci., 4, 117-131, 2004.

Bird, J. F. and Bommer, J. J.: Earthquake losses due to ground failure, Eng. Geol., 74, 147-179, 2004.

Bommer, J., Spence, R., Erdik, M., Tabuchi, S., Aydinoglu, N., Booth, E., del Re, D., and Peterken, O.: Development of an earthquake loss model for Turkish catastrophe insurance, J. Seismology, 6, 431-446, 2002.

Bommer, J. J., Magenes, G., Hancock, J., and Penazzo, P.: The influence of strong-motion duration on the seismic response of masonry structures, Bull. Earthquake Eng., 2, 1-26, 2004.

Borst, D., Jung, D., Murshed, S. M., and Werner, U.: Development of a methodology to assess man-made risks in Germany, Nat. Hazards Earth Sys. Sci., 6, 779-802, 2006.

Cardinali, M., Reichenbach, P., Guzzetti, F., Ardizzone, F., Antonini, G., Galli, M., Cacciano, M., Castellani, M., and Salvati, P.: A geomorphological approach to the estimation of landslide hazards and risks in Umbria, Central Italy, Nat. Hazards Earth Syst. Sci., 2, 57-72, 2002.

Coburn, A. W., Spence, R. J. S., and Pomonis, A.: Vulnerability and risk assessment, Disaster Management Training Programme, UNDP, 2nd edition edn., 1994.

Crowley, H., Bommer, J. J., Pinho, R., and Bird, J.: The impact of epistemic uncertainty on an earthquake loss model, Earthquake Engineering and Structural Dynamics, 34, 1653-1685, 2005.

Dominey-Howes, D. and Papathoma, M.: Validating a tsunami vulnerability assessment model (the PTVA model) using field data from the 2004 Indian Ocean tsunami, Natural Hazards, doi: 10.1007/s11069-006-0007-9, in press, 2006.

Douglas, J.: RISK-NAT (Module 4): Methods and tools for risk evaluation, Progress report RP-54041-FR, BRGM, Orléans, France, http://www.brgm.fr/publication/rechRapportSP. jsp, 2005.

FEMA: HAZUS-MH, Technical manual, Federal Emergency Management Agency, Washington DC, 2003.

Glade, T.: Vulnerability assessment in landslide risk analysis, Die Erde, 134, 123-146, 2003.

Green, B. D. and Rose, W. I.: Volcanic Risk Map for Santa Mara, Guatemala: What can Risk Maps Contribute to Volcanic Hazard Communications?, http://www.geo.mtu.edu/volcanoes/ santamaria/volcrisk/, 2005.

Hollenstein, K.: Reconsidering the risk assessment concept: Standardizing the impact description as a building block for vulnerability assessment, Nat. Hazards Earth Syst. Sci., 5, 301-307, 2005.
King, A. and Bell, R.: RiskScape New Zealand: A multihazard loss modelling tool, in: Proceedings of Earthquake Engineering in the 21st Century (EE-21C) conference, topic 8: Technologies and trends for disaster monitoring and reduction., 2005.

Marzocchi, W., Sandri, L., Gasparini, P., Newhall, C., and Boschi, E.: Quantifying probabilities of volcanic events: The example of volcanic hazard at Mount Vesuvius, J. Geophys. Res., 109, B11201, doi:10.1029/2004JB003155, 2004.

OASIS: Open Advanced System for dISaster and emergency management, http://www.oasis-fp6.org/, 2006.

ORCHESTRA: Open aRCHitEcture and Spatial data infrasTRucture for risk mAnagement, http://www.eu-orchestra.org/, 2006.

Peiris, N.: Vulnerability functions for tsunami loss estimation, in: Proceedings of First European Conference on Earthquake Engineering and Seismology (a joint event of the 13th ECEE \& 30th General Assembly of the ESC), paper number 1121, 2006.

PREVIEW: PREVention, Information and Early Warning preoperational services to support the management of risks, http: //www.preview-risk.com/, 2006.

Ramsbottom, D., Floyd, P., and Penning-Rowsell, E.: Flood risks to people phase $1, \mathrm{R} \& \mathrm{D}$ Technical Report FD2317, Defra/Environmental Agency, Flood and Coastal Defence R \& D Programme, 2003.

Risk Map Germany: Working Program, http://www.cedim.de/ english/166.php, 2006.

Rossetto, T. and Elnashai, A.: Derivation of vulnerability functions for European-type RC structures based on observational data, Engineering Structures, 25, 1241-1263, 2003.

Sedan, O. and Mirgon, C.: Application ARMAGEDOM - Notice utilisateur, Tech. Rep. RP-52759-FR, BRGM, France, in French, 2003.

Spence, R. J. S., Baxter, P. J., and Zuccaro, G.: Building vulnerability and human casualty estimation for a pyroclastic flow: A model and its application to Vesuvius, J. Volcanology Geothermal Res., 133, 321-343, 2004.

Spence, R. J. S., Kelman, I., Baxter, P. J., Zuccaro, G., and Petrazzuoli, S.: Residential building and occupant vulnerability to tephra fall, Nat. Hazards Earth Syst.Sci., 5, 477-494, 2005.

Stewart, M. G.: Cyclone damage and temporal changes to building vulnerability and economic risks for residential construction, Journal of Wind Engineering and Industrial Aerodynamics, 91, 671-691, 2003.

Vecchia, A. V.: A unified approach to probabilistic risk assessments for earthquakes, floods, landslides, and volcanoes. Proceedings of a multidiscipilinary workshop held in Golden, Colorado November 16-17, 1999., Open-File Report 01-324, U.S. Geological Survey, 2001.

WIN: Wide Information Network, http://win-eu.org/, 2006. 